\title{
Patient engagement in the design of clinical research in Noonan syndrome spectrum disorders: a scoping review
}

\author{
Dagmar K. Tiemens ${ }^{1,6}$, Jacqueline Nugteren ${ }^{1}$, Erika Leenders² , Ellen Wingbermühle ${ }^{2,3,4}$, \\ Carina A. C. M. Pittens ${ }^{5}$ and Jos M. Th. Draaisma ${ }^{1 *}$ (I)
}

\begin{abstract}
Background: Noonan syndrome spectrum disorders are a group of disorders caused by mutations in several genes of the RAS/MAPK pathway. Because of a highly heterogeneity and variable phenotypical manifestations of the disorders, these children and adults have a variable number of symptoms. Inclusion of their perceived experience of their health and developmental problems in research (design) could contribute to increased relevance of the research process and outcomes. The aim of this study is to get insight in what way patients with a Noonan syndrome spectrum disorder have been involved in the research process in order to learn for future engagement practices.
\end{abstract}

Methods and results: To that end, the degree of engagement was measured by the eight levels of the participation ladder of Arnstein. Using a scoping review approach, 18 articles were selected in which patient engagement in the design of studies in patients with Noonan syndrome spectrum disorders was described over the past twenty years. Six of these articles reported engagement on the level of informing (level 3), 8 on the level of consultation (level 4), 2 on the level of placation (level 5)and 2 on the level of partnership (level 6).

Conclusions: The current results do show a positive albeit still modest development of patient engagement over the last few years. A promising way to stimulate engagement is aiming to yield insights in the most important patients' needs by developing a patient guided research agenda. However, this is not automatically followed by patient engagement at higher levels of participation in subsequent research steps. For this reason, in the Netherlands for example, a Dutch Noonan syndrome spectrum disorders research agenda is being developed, in a collaboration between the Dutch Noonan Syndrome Foundation and national scientific and clinical professionals.

Keywords: Noonan syndrome spectrum disorders, RAS/MAPK pathway, Patients, Participation, Level of engagement, Research, Ladder of Arnstein

\section{Introduction}

Noonan syndrome spectrum disorders are a group of of phenotypically related conditions, resembling Noonan syndrome, characterized by a constitutional

\footnotetext{
*Correspondence: jos.draaisma@radboudumc.nl

${ }^{1}$ Department of Pediatrics, Amalia Children's Hospital, Radboud Institute for Health Sciences, Radboud University Medical Center, Nijmegen, The Netherlands

Full list of author information is available at the end of the article
}

dysregulation of the Ras/mitogen-activated protein kinase (Ras/MAPK) signaling pathway and a highly variable expressivity $[1,2]$. One out of 1.000 to 2.500 live births has a RASopathy syndrome [3, 4]. Classically, these syndromes have been described as clinically distinct syndromes, including Noonan syndrome (NS; MIM\#163950), cardiofaciocutaneous syndrome (CFCS; MIM\#115150), Costello syndrome (CS; MIM\#218,040), Noonan syndrome with multiple lentigines (NSML; MIM\#151100) and Noonan-like syndrome with loose original author(s) and the source, provide a link to the Creative Commons licence, and indicate if changes were made. The images or other third party material in this article are included in the article's Creative Commons licence, unless indicated otherwise in a credit line to the material. If material is not included in the article's Creative Commons licence and your intended use is not permitted by statutory regulation or exceeds the permitted use, you will need to obtain permission directly from the copyright holder. To view a copy of this licence, visit http://creativecommons.org/licenses/by/4.0/. The Creative Commons Public Domain Dedication waiver (http://creativeco mmons.org/publicdomain/zero/1.0/) applies to the data made available in this article, unless otherwise stated in a credit line to the data. 
anagen hair (NS-LAH; MIM\#607721), with clinical overlap between the different syndromes [1]. At this moment, at least 19 genes have been found to be associated with the Noonan syndrome spectrum disorders [1].

During the last decades, the perspectives of patients, caregivers and disease advocacy organisations have become increasingly important in the design, planning and execution of health research [5, 6]. Experiential knowledge of patients can be complementary to the expert knowledge of researchers, or can give a different perspective on current knowledge (substantive arguments) $[5,7]$. Additionally, patients can be considered 'end users' of developed knowledge and should therefore be involved in medical scientific research affecting them (normative argument) [8]. Finally, prioritizing their problems and complaints gives patients a say in what is felt the most important. Such an active role for patients, care givers and disease advocacy organisations in the development and execution of research can increase the amount of research on that specific condition and enhance the support for and participation in studies (political arguments) [9].

Integrating patients' experiences in health research policy making-particularly in a research agenda setting-could provide for a wider perspective to health research and care, and thereby contribute to increased quality and relevance of studies [5, 6, 10]. Especially for patients with a Noonan syndrome spectrum disorder the inclusion of patients' experiences is relevant since the heterogeneity and variable phenotypical manifestations of these disorders leads to a variable number of symptoms and complaints. Alignment of the experiences and needs of patients to research results in more relevant research process and outcomes.

In 2014 a systematic review was published on approaches for engaging patients in clinical research on rare diseases [11]. In this review no publications were reported of the engagement of patients, caregivers or patient organizations into the planning and/or conduct of research on one of the different Noonan syndrome spectrum disorders.

This article aims to explore how and to what degree individuals with a Noonan syndrome spectrum disorder (patients), their relatives and their representatives, were engaged in clinical research since the first gene associated with Noonan syndrome was detected in January 2001. To provide for an overview of engagement, various aspects of research were examined: type of clinical research, various ways of patient representation and the six steps of the research process, using the model of Rummel and Ballaine [12]. The participation Ladder of Arnstein, an eight level tool to measure degrees of engagement and decision making power, was used to clarify the way patients were engagement in each of these aspects [13]. The information this provides may be helpful to improve patient engagement in future research and thereby contribute to increased relevance of research outcomes to patients with a Noonan syndrome spectrum disorder.

\section{Materials and methods \\ General}

This study adopted a scoping review approach. The scoping review (or scoping study) is a strategy designed to map literature in a research area, identifying key concepts, sources of evidence, and research gaps [14, 15]. Scoping reviews are particularly helpful in studying literature in research areas with emerging evidence. The methodology employed in this study was drawn from the commonly-used framework proposed by Arksey and O'Malley and advanced by Levac, Colquhoun and O'Brien $[14,15]$. This rigorous approach involves five key stages: (stage 1) identifying the research question, (stage 2) identifying relevant studies, (stage 3) study selection (this study used the PRISMA Flow chart), (stage 4) data extraction, and (stage 5) collecting, summarizing and reporting the results.

Search results were limited to English, Dutch and German texts and publication date from January first 2001 through July 2020, because of the discovery of the first Noonan syndrome related gene in January 2001 [16]. Search results were limited to (development of) clinical studies. Articles about proceedings of a symposium, in which patients or their representatives and the development and implementation of a management guideline were included in this search as well, as clinical guidelines can be considered the result of scientific research, the discussion based on it and subsequent opinion formation [17]. Grey literature was not included.

\section{Identifying the research questions}

The research questions addressed in this scoping review were defined as:

1. In what kind of clinical research have patients, their relatives and/or their representatives been engaged? (Article characteristics, type of article and year of publication).

2. In what way have patients been represented?

3. What was the level of engagement in each of the six research steps as defined by Rummel and Ballaine [12]?

4. What was the level of engagement according to the ladder of Arnstein [13] and did the degree or level of engagement differ looking at type of clinical research and at each of the six research steps?

5. Did the level of engagement change over time? 


\section{Identifying relevant studies}

Five electronic databases (PubMed, Embase, Web of Science, Medline and Google scholar) were searched using the following Boolean search strategy identified through input from the research team and consultation of the university-affiliated librarian: (type of) Noonan syndrome spectrum disorder AND (means of) engagement AND patient and their synonyms. Both subject headings (such as $\mathrm{MeSH}$ ) and free text terms were applied. The initial search was on 17 July, 2020. The search strategy for Pubmed is provided in Table 1 .

\section{Study selection}

Two authors independently screened all article titles and abstracts to determine eligibility for full text review addressing the research questions. Discrepancies between reviewers were resolved by discussion and consensus or involvement of a third reviewer. Full texts of all remaining studies were retrieved and assessed independently by the same authors based on the same criteria and methods applied in title and abstract screening. To supplement this search, reference lists of reviews and included studies were scanned (so-called snow-balling strategy), and the "related articles" feature of Pubmed was used. Search results were collected and deduplicated in Endnote and then exported into Rayyan software for ease of management [18]. No methodological quality assessment was performed, as scoping reviews aim to map existing evidence and not to present a judgement regarding the 'weight' of evidence [14].

\section{Data extraction}

One author analysed the data of all included studies. The data abstraction chart was drafted collectively and validated independently by one other reviewer in a random sample of 10 articles, after which additional categories were added in an iterative process. The final form included the following criteria:

\section{Article characteristics}

Authors and year of publication.

\section{Types of articles}

These were distinguished according to its content in an iterative process.

1. Research: Articles describing the results of a clinical study

2. Proceedings: Articles describing proceedings of a meeting/congress

3. Guidelines: Articles describing clinical management guidelines

\section{Ways in which patients were represented}

These were defined as:

1. Individuals with a Noonan syndrome spectrum disorder (patients)

2. Patients represented by relatives

3. Patient representative organizations (including family support groups and disease advocacy organisations)

\section{Research step 1 to 6}

These steps were defined using the model of Rummel and Ballaine [12].

1. Step 1: identifying the general study

2. Step 2: choosing the research topic

Table 1 The search strategy for Pubmed

\begin{tabular}{lll}
\hline Noonan syndrome spectrum disorder & (Type of) engagement & Patient and their representation \\
\hline Noonan syndrome & Community participation & Patient \\
Noonan & Policy making & Patients \\
Costello syndrome & Decision making & Patient participation \\
Cardiofasciocutaneous syndrome & Cooperative behaviour & Parent \\
Cardio-facio-cutaneous syndrome & Cooperative & Relatives \\
CFCS & Recruit & Patient federation \\
Loose Anagen Hair syndrome & Volunteer & Patient representative organisation \\
Loose anagen hair & Empowerment & Participation \\
Leopard syndrome & Participate \\
LEOPARD syndrome & Shared decision \\
RASOpathy & Patient activation \\
& Engagement \\
& Collaboration \\
\end{tabular}


3. Step 3: formulating plan and technology

4. Step 4: collecting data

5. Step 5: analyzing and interpreting data

6. Step 6: writing content and other ways of presenting the findings

In every step patients or patient representative groups may be involved. Involvement of recruitment of patients was interpreted as part of step 4. Involvement in development and publication of a guideline may be seen as step 5 and 6.

\section{Levels of engagement}

To measure the level or degree of engagement of the patients and representatives in the included articles, Arnstein's ladder of citizen participation was used (Fig. 1) [13]. This approach distinguishes between so-called "powerholders" on one hand with unlimited access to information and decision making power (the researchers in the analyzed studies) and the so-called "powerless" with limited access to information and decision making power (patients and/or their representatives).

The ladder distinguishes 8 levels of participation and decision making power of the "powerless". The bottom levels of the ladder are (1) manipulation or education and (2) therapy or curing. In this context, these levels describe the participation of patients as objects of study, and not as being actively engaged in the development and execution of the research process. Studies with engagement at

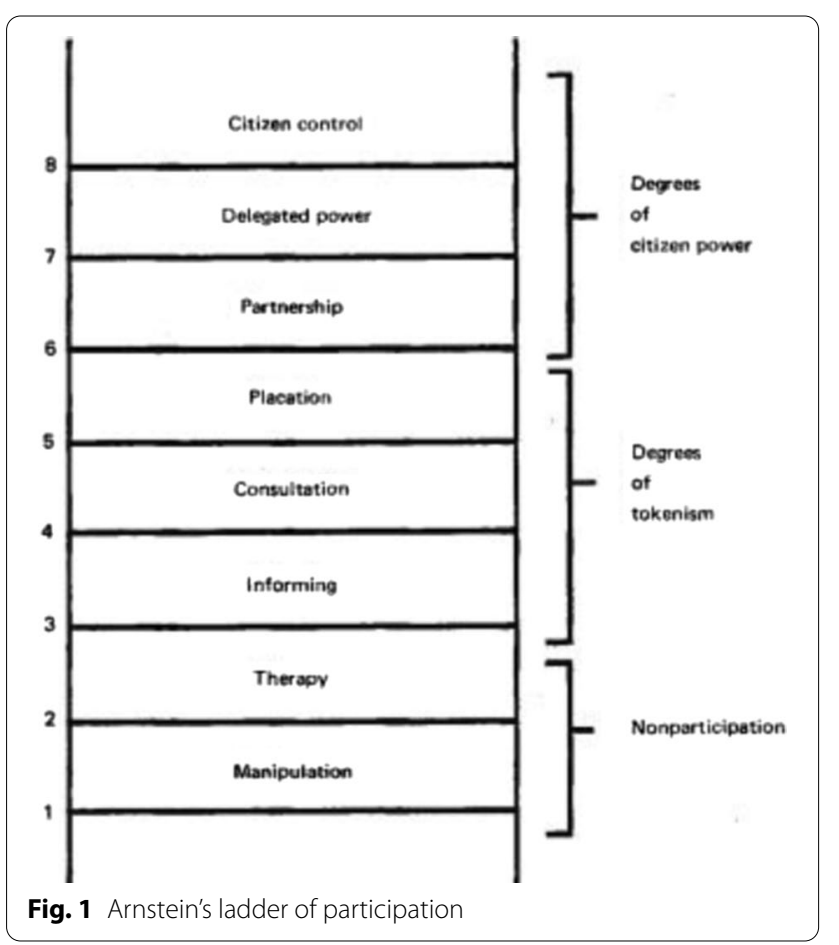

these levels were excluded. Levels (3), (4) and (5) progress to levels of "tokenism" that allow the participants to be "informed", but without a channel of feedback (level 3) or to have a voice in consultation (level 4). In studies with participation at these levels, patients may indeed hear and be heard, but they lack the power to ensure that their views will be used by the powerholders. For example, in this context, level 3 includes the engagement of disease advocacy groups in patient recruitment.

Further up the ladder are levels with increasing degrees of decision-making power. At level 5 (placation), patients may advise or plan ad infinitum, but researchers ("traditional powerholders") retain the right to judge the legitimacy or feasibility of the advice. Patients can enter into a partnership (6) that enables them to negotiate and engage in trade-offs with the researchers. At the topmost steps, (7) delegated power and (8) citizen control, patients obtain the majority of decision-making seats, or full managerial power [8].

Finally, to examine the level of engagement within the categories, the level on the ladder of Arnstein per subtype within each category was determined.

\section{Results}

Identifying relevant studies and study selection

After searching 5 databases (Pubmed, Cochrane, Embase, Web of science and Google scholar), 383 articles met previously described search terms. These articles were deduplicated, which led to 300 individual articles. The article titles and abstracts of these articles were uploaded in Rayyan and screened.

They were first screened on relevance and inclusion criteria according to title and abstract, which excluded 257 articles and then on full article, which excluded 29 articles. The 14 articles that were left, were included in this review. Four additional articles could be included after scanning of the reference lists of the included articles (Fig. 2), which led to 18 included articles in total.

The characteristics of the included articles are presented in Table 2, and further elaborated on the next sections.

Some of the characteristic examples of the level of engagement of the different articles are given in Table 3.

\section{In what kind of research have patients and/or their representatives been engaged?}

Out of the 18 selected articles, eight (47\%) described the results of a clinical research study that was performed, eight articles described the proceedings of a symposium/ meeting and two articles described the development of guidelines. From the eight articles with a clinical research study, three articles $[19,21,26]$ presented results about (neuro)behavioral aspects, two about motor problems 


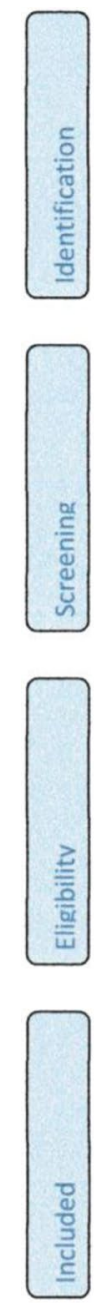

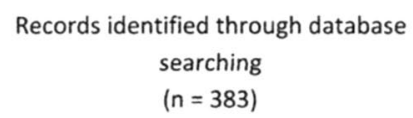

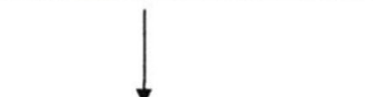

Records after duplicates removed ( $n=83$ )
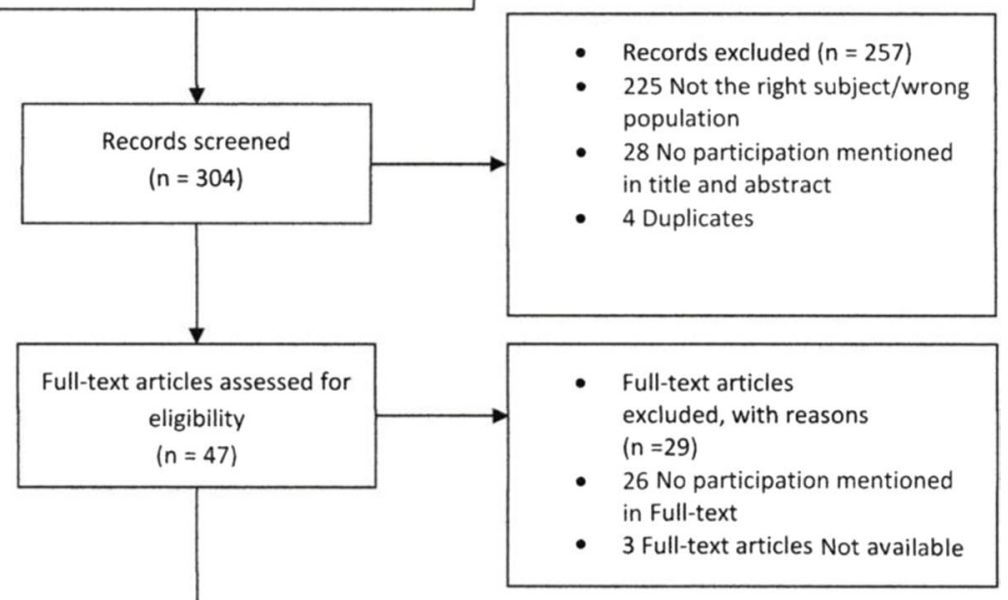

Studies included in qualitative synthesis $(n=18)$

Fig. 2 Prima flowchart for study selection

$[20,26]$, one about incontinence [28], one about prenatal findings [34], one about further delineation of a phenotype [23] and one about reclassification of a gene variant [22]. There were eight articles in which the proceedings from a RASopathy symposium/meeting were described $[4,24,25,27,30-33]$, of which one article described the proceedings from of a Costello syndrome research symposium [30]. Two articles described guidelines as a result on a symposium on NS and CFCS $[3,31]$.

\section{In what way have patients been represented in the included articles?}

In seven of the 18 articles in which the results of a research study were described, recruitment took place through a patient representative organization [19-21, 23, $26,28,34]$. For example, patients were recruited at the 2003 and 2005 International Costello syndrome meetings $[19,23]$. For a study on incontinence in patients with
Noonan syndrome in Germany, 19 children (5-17 years) and 10 adults (18-48 years) were recruited through a German parent support group [28]. In the eighth article, the authors were contacted by a mother with a specific (research) question about the pathogenicity of a BRAF variant [22].

In the eight articles in which the proceedings of a meeting/symposium are described, patients and/or patient representative organizations participated explicitly. The first time this was reported concerned the 1st International Costello Syndrome Research Symposium in 2007 [30]. This symposium brought clinicians, scientists and individuals with Costello syndrome and their families together.

Two articles described (the development of) a guideline, which was developed together with a patient representative organization $[3,31]$. Although there was no patient involvement in the design of Noonan syndrome 


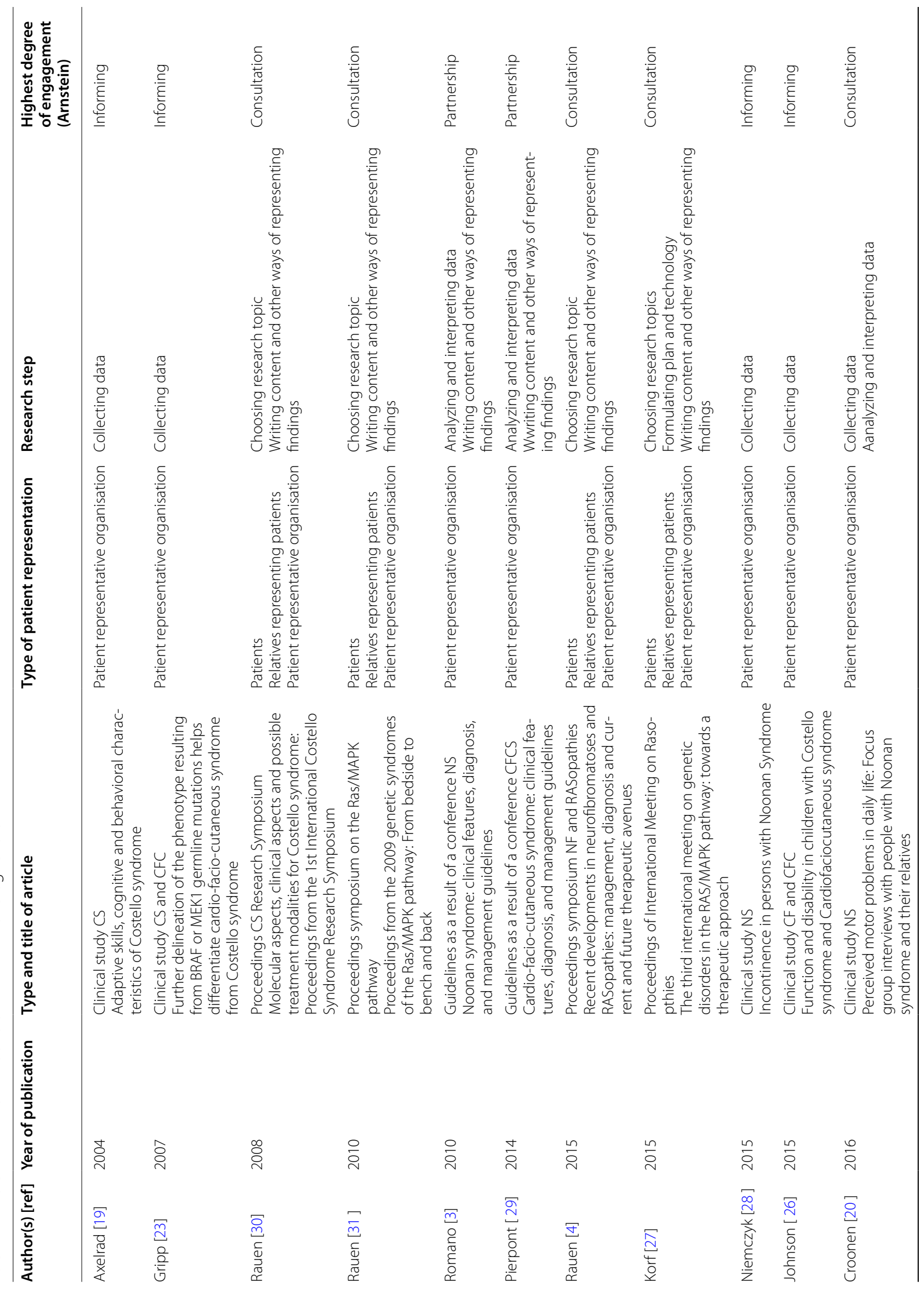




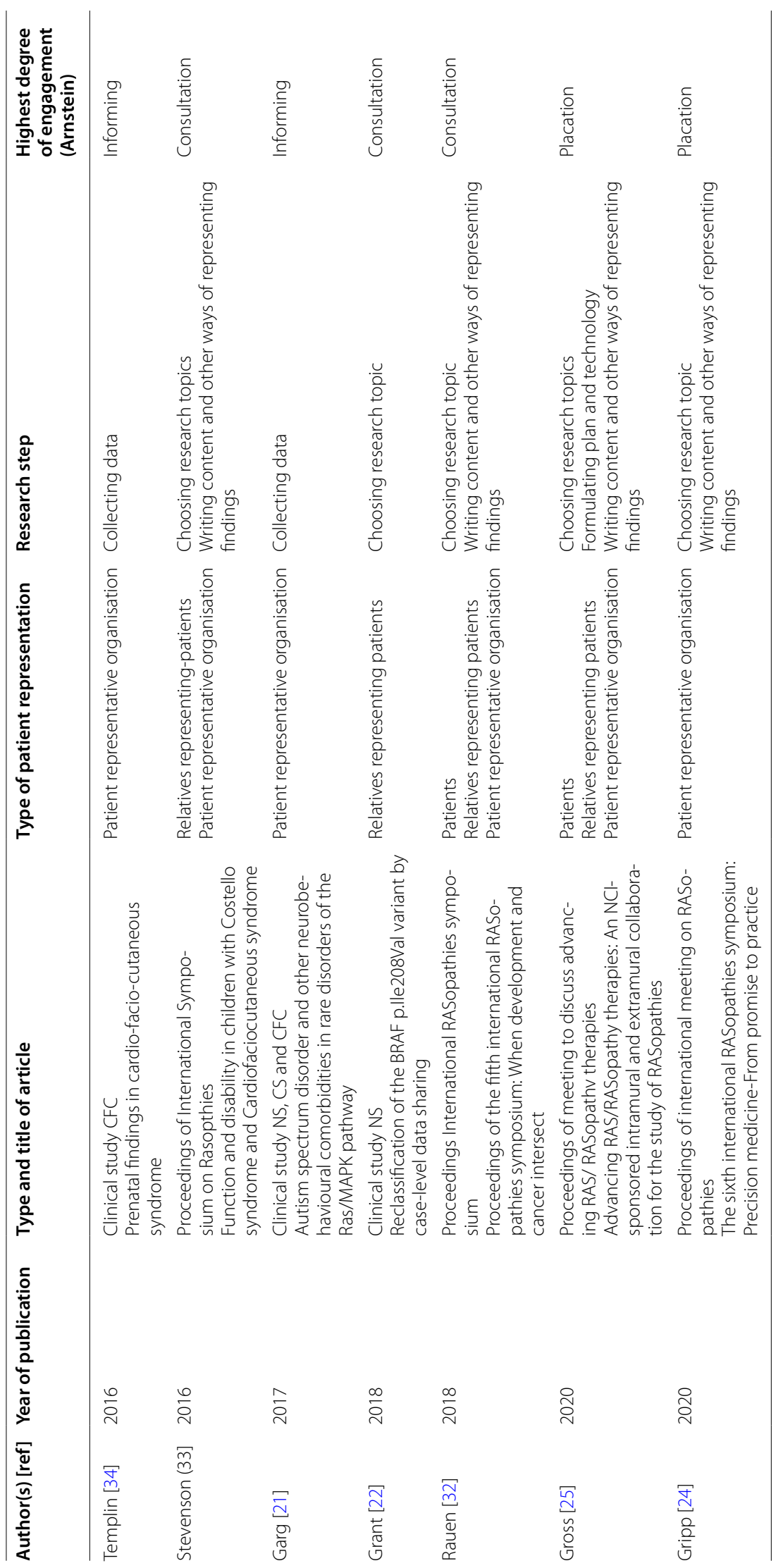


Table 3 Some of the characteristic example of level of engagement as cited in the different articles

\begin{tabular}{|c|c|c|}
\hline Author(s) [ref] & Year of publication & Characteristic example of level of engagement \\
\hline Axelrad [19] & 2004 & $\begin{array}{l}\text { "Through the 3rd International Costello Syndrome Conference, families attending the conference whose child } \\
\text { had a clear diagnosis of Costello Syndrome and was between age } 2 \text { and } 21 \text { years were contacted for participa- } \\
\text { tion in this research study" }\end{array}$ \\
\hline Gripp [23] & 2007 & $\begin{array}{l}\text { "Patients clinically diagnosed with Costello syndrome were identified at the } 2003 \text { and } 2005 \text { International Cos- } \\
\text { tello Syndrome Meetings, through the Costello Syndrome Family Network and through physician referral" }\end{array}$ \\
\hline Rauen [30] & 2008 & $\begin{array}{l}\text { "Patients clinically diagnosed with Costello syndrome were identified at the } 2003 \text { and } 2005 \text { International Cos- } \\
\text { tello Syndrome Meetings, through the Costello Syndrome Family Network and through physician referral" }\end{array}$ \\
\hline Rauen [31 ] & 2010 & $\begin{array}{l}\text { "This unprecedented NIH-sponsored symposium was held in conjunction with family conferences sponsored } \\
\text { by the Noonan Syndrome Support Group (NSSG), the Costello Syndrome Family Network (CSFN) and the Inter- } \\
\text { national Costello Syndrome Support Group (ICSSG), CFC International" }\end{array}$ \\
\hline Romano [3] & 2010 & $\begin{array}{l}\text { "The Noonan Syndrome Support Group convened a conference of health care providers, all involved in vari- } \\
\text { ous aspects of NS, to develop these guidelines for use by pediatricians in the diagnosis and management of } \\
\text { individuals with NS and to provide updated genetic findings" }\end{array}$ \\
\hline Pierpont [ 29] & 2014 & $\begin{array}{l}\text { "To address this need, CFC International, a nonprofit family support organization that provides a forum for } \\
\text { information, support, and facilitation of research in basic medical and social issues affecting individuals with } \\
\text { CFC, organized a consensus conference" }\end{array}$ \\
\hline Rauen [4] & 2015 & $\begin{array}{l}\text { "The international symposium "Recent Developments in Neurofibromatoses and RASopathies: Management, } \\
\text { Diagnosis and Current and Future Therapeutic Avenues" was attended by clinicians, basic scientists, physician- } \\
\text { scientists, clinical and molecular geneticists, advocate leaders, genetic counselors, trainees, students and } \\
\text { individuals with Ras/MAPK syndromes and their families" }\end{array}$ \\
\hline Korf [27] & 2015 & $\begin{array}{l}\text { "Parent and patient advocates opened the meeting with a panel discussion to set the stage regarding their } \\
\text { hopes and expectations for therapeutic advances" }\end{array}$ \\
\hline Niemczyk [28 ] & 2015 & $\begin{array}{l}\text { "Nineteen children (5-17 years) and } 10 \text { adults (18-48 years) with NS were recruited through a German parent } \\
\text { support group" }\end{array}$ \\
\hline Johnson [ 26] & 2015 & $\begin{array}{l}\text { "Participants were recruited from the International Costello Syndrome Family Forum and the CFC International } \\
\text { Conference in Orlando, Florida in August 2013. Participants with Noonan syndrome were also recruited at the } \\
\text { conference" }\end{array}$ \\
\hline Croonen [20 ] & 2016 & $\begin{array}{l}\text { "The study was conducted in collaboration with the Dutch Noonan syndrome patient association. Participants } \\
\text { were recruited through an announcement for one of three planned focus group interviews on the flyer of the } \\
\text { Noonan syndrome contact day" } \\
\text { "The analyzed data were presented on the NS contact day. All attendees agreed with the results without any } \\
\text { additional remark" }\end{array}$ \\
\hline Templin [34] & 2016 & "Parents of CFC patients were contacted through referring clinicians and the family support group" \\
\hline Stevenson (33] & 2016 & $\begin{array}{l}\text { "The symposium is unique in its approach as it is held in conjunction with multiple advocacy meetings for } \\
\text { RASopathy family/patient support groups. A poster session of submitted scientific abstracts and invited posters } \\
\text { for representative parent/patient support groups was held to open the symposium allowing for interaction and } \\
\text { discussion between the lay community and the scientific community" }\end{array}$ \\
\hline Garg [21] & 2017 & $\begin{array}{l}\text { "The study was also advertised on newsletters, family information days, and on the social media of Noonan, } \\
\text { Costello, and CFC syndrome charities } \\
\text { and the Noonan Syndrome Association (UK) and Costello Kids for their help with recruitment" }\end{array}$ \\
\hline Grant [22] & 2018 & "Our laboratory was contacted by the mother of Proband 1" \\
\hline Rauen [32] & 2018 & $\begin{array}{l}\text { "Clinicians, basic scientists, physician-scientists, advocate leaders, trainees, students, and individuals with RASo- } \\
\text { pathies and their families attended" } \\
\text {..The patient and family advocates strongly requested the researchers and medical experts to stay interested in } \\
\text { issues that adults live with and to continue to heed advocacy support groups" }\end{array}$ \\
\hline Gross [25] & 2020 & $\begin{array}{l}\text { "A multidisciplinary group of } 38 \text { care providers, basic scientists, and representatives from the patient advocacy } \\
\text { group RASopathiesNet........ aimed to define the RASopathies and RASopathy-associated genes for the pur- } \\
\text { poses of ART, identify the available tools for translational research in the RASopathies, describe the longitudinal } \\
\text { cohort study that is the cornerstone of ART, and discuss potential solutions for the various challenges that have } \\
\text { hindered investigators from initiating therapeutic clinical trials for individuals with RASopathies to date } \\
\text { Outreach activities through RASopathiesNet and the syndrome-specific family groups have indicated that } \\
\text { individuals with a RASopathy are eager to engage in the scientific process" }\end{array}$ \\
\hline Gripp [24] & 2020 & $\begin{array}{l}\text { "This meeting brought together basic science researchers, clinicians, clinician scientists, patient advocates, } \\
\text { and representatives from pharmaceutical companies and the National Institutes of Health. Novel RASopathy } \\
\text { genes, variants, and animal models were discussed in the context of medication trials and drug development. } \\
\text { Attempts to define and measure meaningful endpoints for treatment trials were discussed, as was drug avail- } \\
\text { ability to patients after trial completion" }\end{array}$ \\
\hline
\end{tabular}


spectrum diseases clinical studies underlying the guidelines, the patient representative group was a partner in the interpretation of study results and the implementation of these results in the guidelines.

How was the engagement in each of the six research steps? We found no article that included patient engagement in the entire research trajectory. Eight of the articles reported about engagement of patients/patient representatives organizations in the choice of the research topic (research step 2) [4, 24, 25, 27, 30-33]. In two articles patients were involved in the formulation of the plan and the technology of the clinical research study (research step 3) [25, 27]. In one of these studies the results of an initiating meeting were presented [25]. The participants aimed to define the non-NF1 RASopathies and RASopathy-associated genes for the purposes of Advancing RAS/RASopathy Therapies, identify the available tools for translational research in the non-NF1 RASopathies, describe the longitudinal cohort study, and discuss potential solutions for the various challenges that have hindered investigators from initiating therapeutic clinical trials for individuals with non- NF1 RASopathies to date.

Seven out of the 18 articles (39\%) reported only participation in step 4 (recruitment of patients or data collection). For example, Axelrad et al. (2004) reported that patients for their study on adaptive skills, cognitive, and behavioral characteristics of Costello Syndrome were recruited by means of the 3rd International Costello Syndrome Conference [19].

Three articles reported participation in step 5, analyzing and interpretation of the data $[3,20,31]$. One study in addition to recruitment of patients [20]. They presented their study data on the Noonan syndrome contact day one year after the study was performed for interpretation and discussion on the data. Patient representative organizations were engaged in the process of analyzing and interpreting the data (research step 5) and writing the guidelines (research step 6) [3, 31]. In the eight articles in which the proceedings of a meeting/symposium are described, patients and/or patient representative organizations participated explicitly [4, 23, 25, 27, 30-33]. All these eight articles were also written by members of the patient representative organizations (research step 6).

\section{What was the level of engagement according to the ladder of Arnstein?}

Six of the 18 articles reported participation on level 3 (informing) (33\%), 8 on level 4 (consultation) (44\%), 3 on level 5 (placation) (11\%), and 2 on level 6 (partnership) (11\%). There were no reports found on the two highest levels of participation (7 and 8).
In six out of eight of the articles about clinical research studies, participation took place at the level of informing (level 3). For example, in the article of Templin et al. (2016), prenatal features were extracted from a national database and additional data were collected from 16 families contacted and recruited through the French association of CFC-Costello syndrome [34]. In none of these six articles another engagement of the patient representative organization was mentioned than the help of the recruitment of patients to make a research study possible.

In two of the eight articles about clinical research studies, the (highest) level of participation was consultation $[22,26]$. The study by Croonen et al. (2016) was conducted in collaboration with the Dutch Noonan Syndrome Foundation [26]. Participants were recruited through an announcement for one of three planned focus group interviews on the flyer of the Noonan syndrome contact day in 2013, where focus group interviews were conducted (information: level 3). There-after the analyzed data were presented to discuss the results on the Noonan syndrome contact day in 2014. As patients had the opportunity to hear the results and had the choice to make comments, engagement in this study was scored at level 4 (consultation). In another study the mother of a patient came to the laboratory with a request for a study, and was heard [22]. She received a report of a variant in $B R A F$ following prenatal RASopathy testing. The variant had been previously classified by this laboratory as a Variant of Unknown Significance, which prompted reevaluation of the variant. Multiple sources of case-level data as well as the presence of the variant in the general population yielded sufficient evidence to reclassify the variant as likely benign. This reclassification alleviated significant concern for the family, and the child was born healthy with no clinical manifestations of Noonan syndrome or a RASopathy.

In the articles about the proceedings of symposiums the general level (six out of eight) of engagement was consultation (level 4). The first symposium/meeting reported on was the 1st International Costello Syndrome Research Symposium in 2007 [30]. The symposium occurred in conjunction with the Costello Syndrome Family Network (CSFN) conference bringing together clinicians, scientists, physician-scientists, advocate leaders, trainees, students and individuals with Costello syndrome and their families. The overall goal of the symposium was to provide an open forum for researchers, clinicians, and physician-scientists to share and discuss basic science and clinical issues setting forth a solid framework for future research, translational applications directed towards therapy and best practices for individuals with CS. At this symposium one of the patients presented the problems she encountered. This article about proceedings of a 
symposium was followed by more articles about the same type of symposia/meetings [4, 27, 31-33].

In two articles a higher level of participation, placation (level 5), could be found. In the article of Gross et al. (2020), the authors (including three members of the patient representative organization) describe the goals of the meeting [25]. However, the method of the participation of patients and their representatives in the followup process is not made clear [25]. In the article of Gripp et al. (2020), the authors (including eight members of different patient representatives organizations) emphasized the added values of the patient perspectives:"Patient advocates highlighted pain, plexiform neurofibromas, intractable seizures, neurocognitive function, and social skills as the most urgent treatment targets. Further studies on how RASopathies impact the lives of adults were requested [24]."

In two articles (including authors from the patient representatives organizations) guidelines for NS and CFCS were formulated $[3,31]$. Although not a report of an original research study, these guidelines were formulated in a consensus meeting, coordinated by the patient representatives organizations with health care providers with expertise in various aspects of the disorders, with the aim of developing guidelines for diagnosis and clinical management. These reports are the result of those efforts and

Table 4 Level of engagement per type of article, measured with Arnsteins' participation ladder

\begin{tabular}{lll}
\hline Type of article & $\begin{array}{l}\text { Number of } \\
\text { studies }\end{array}$ & Scores on Arnsteins' ladder \\
\hline Clinical study & 8 & $\begin{array}{l}\text { Informing (level 3): } 5 \text { times } \\
\text { Consultation (level 4): } 3 \text { times } \\
\text { Consultation (level 4): } 6 \text { times } \\
\text { Placation (level 5): } 2 \text { times }\end{array}$ \\
Guideline & 8 & Partnership (level 6): 2 times \\
\hline
\end{tabular}

are intended to provide pediatricians and other specialists with information of key clinical features of NS and CFCS, to provide an update of currently understood genetic causes, and to present management recommendations. This may be seen as a form of partnership (level 6).

Although the number of articles of clinical studies with patient engagement is equal to the number of proceedings, the median score of engagement measured by Arnsteins' participation ladder, as shown in Table 4, is the lowest in articles of clinical studies (informing). The highest level was found in articles that describe the development of guidelines (partnership). Articles describing proceedings had most often the level of consultation.

Looking at the amount of the included clinical articles, patient engagement was seen most often in step 6 (writing content and other ways of presenting the findings) of the research process, followed by step 2 (choosing the research topic) and step 4 (collecting data). Only a few studies were found with patient engagement in step 5 (analyzing and interpreting data) and step 3 (formulating plan and technology).

However, looking at the level of engagement measured by Arnsteins' participation ladder, the highest median level was found when patients were involved in analyzing and interpreting data (research step 5), with placation (level 5) (Table 5). Choosing the research topic (step 2) and writing content and other ways of presenting data (step 6) had a median level between consultation and placation (between level 4 and 5). Research step 4 (collecting data) showed the lowest median level of patient engagement (informing, level 3).

\section{What was the change over time?}

Over the last twenty years there is a modest, but clear increase in the amount of articles in which Noonan syndrome spectrum disorder patients participated in the

Table 5 Level of engagement in the six research steps in the included 18 articles, measured with Arnsteins' participation ladder

\begin{tabular}{|c|c|c|}
\hline Research step & Total of 18 articles & Level on Arnsteins' ladder \\
\hline Step 1 Identifying the general study & 0 & \\
\hline Step 2 Choosing the research topic & 9 & $\begin{array}{l}\text { Consultation (level 4): } 7 \text { times } \\
\text { Placation (level 5): } 2 \text { times }\end{array}$ \\
\hline Step 3 Formulating plan and technology & 2 & $\begin{array}{l}\text { Consultation (level 4): } 1 \text { time } \\
\text { Placation (level 5): } 1 \text { time }\end{array}$ \\
\hline Step 4 Collecting data & 7 & $\begin{array}{l}\text { Informing (level 3): } 6 \text { times } \\
\text { Consultation (level 4): } 1 \text { time }\end{array}$ \\
\hline Step 5 Analyzing and interpreting data & 3 & $\begin{array}{l}\text { Consultation (level 4): } 1 \text { time } \\
\text { Partnership (level 6): } 2 \text { times }\end{array}$ \\
\hline Step 6 Writing content and other ways of presenting the findings & 10 & $\begin{array}{l}\text { Consultation (level } 4 \text { ): } 6 \text { times } \\
\text { Placation (level 5): } 2 \text { times } \\
\text { Partnership (level 6): } 2 \text { times }\end{array}$ \\
\hline
\end{tabular}


process on research focusing on their health. From one study in 2000-2005, four studies in 2006-2010, five studies in 2011-2015 to eight studies in 2016-2020. Although the score of participation level (consultation, level 4) remained the same over the years (data not shown), the amount and diversity of the research steps patients were engaged has increased. (Table 6).

\section{Discussion}

The aim of this scoping review was to get insight into what extent and in what way patients with a Noonan syndrome spectrum disorder and/or their representatives have been involved in one or more phases of clinical research and indicate the level of patient engagement in health research on Noonan syndrome spectrum disorders. This way, we hope to gain insight into how patients can become engagement more and better in future research and thereby having more impact on the process and outcomes of research. Although Forsythe et al. (2014) could not identify any articles with patient engagement in clinical research on Noonan syndrome spectrum disorders in 2014, we could identify five articles dated before 2014 with patient engagement in research, probably due to the use of another search strategy and/ or other inclusion criteria [11]. Our scoping review could identify 18 articles with patient engagement in clinical research on Noonan syndrome spectrum disorders over the last 20 years.

The lowest median level of participation was found in clinical studies, even though the amount of clinical studies in the included articles was relatively high. No evidence was found that patients had participated in all six steps of the research process, though in recent years the number of articles which reports patient engagement have been increased, not only in quantity, but also in the variety and number of research steps. Only three studies were found with patient engagement in analyzing and interpreting data (research step 5), but when patients did engage in this step, the engagement level had the highest level (level 5, placation). The lowest level of engagement was found when patients were engaged in collecting data (step 4).

These findings suggest that patient engagement over the last two decades has mostly been at the level of informing (level 3 on the 8 levels of participation at the ladder of Arnstein) or consultation (level 4), by bringing the researchers and the patients and/or their representatives together. A positive finding is the observation that in recent years reporting about patient engagement seems to have been increased.

A social/cultural change of the position of patients may be a reason for the increase of engagement in the number of steps of the research process, the relatively high degree of patient empowerment when engagement takes place during the analyzing and data interpreting stage of the research process (step 5) or engagement in the development of management guidelines. This is also reflected in changes in policies and the emergence of institutes. For instance, in 2010 the Patient-Centered Outcomes Research Institute, an independent nonprofit, nongovernmental organization authorized by the congress was created in the United States. This institute funds studies that address methods for improving engagement, for evaluating the impact of engagement on research outcomes, and for assuring that study questions and outcomes are meaningful to patients [35]. Moreover, the European Reference Network Ithaca, in which the Noonan syndrome spectrum disorders are incorporated, is a patient centered network which meets the needs of those with rare congenital malformation and syndromes with intellectual and other neurodevelopmental disorders [36]. All activities of Ithaca include patients, their families and lay organizations as equal partners in a network aiming at developing best practices and initiating guideline development.

There are many patient representative organizations, for example the French Costello Group, CFC International, the Dutch Noonan syndrome Foundation,

Table 6 Number of studies in which Noonan syndrome spectrum disorder patients were engaged in a particular step in research over the last twenty years

\begin{tabular}{|c|c|c|c|c|c|c|c|}
\hline $\begin{array}{l}\text { Year of } \\
\text { publication }\end{array}$ & $\begin{array}{l}\text { Total number of } \\
\text { studies (total } n \text { ) }\end{array}$ & $\begin{array}{l}\text { Step } 1 \\
\text { Identifying the } \\
\text { general study } \\
\text { (n) }\end{array}$ & $\begin{array}{l}\text { Step } 2 \text { Choosing } \\
\text { the research } \\
\text { topic (agenda } \\
\text { setting) (n) }\end{array}$ & $\begin{array}{l}\text { Step } 3 \\
\text { Formulating } \\
\text { plan and } \\
\text { technology }(n)\end{array}$ & $\begin{array}{l}\text { Step } 4 \\
\text { Collecting } \\
\text { data }(n)\end{array}$ & $\begin{array}{l}\text { Step } 5 \\
\text { Analyzing and } \\
\text { interpreting } \\
\text { data }(\mathrm{n})\end{array}$ & $\begin{array}{l}\text { Step } 6 \text { Writing } \\
\text { content and } \\
\text { other ways of } \\
\text { presenting data } \\
\text { (n) }\end{array}$ \\
\hline 2000-2005 & 1 & & & & 1 & & \\
\hline 2006-2010 & 4 & & 2 & & 1 & 1 & 3 \\
\hline $2011-2015$ & 5 & & 2 & 1 & 2 & & 4 \\
\hline 2016-2020 & 8 & & 5 & 1 & 3 & 1 & 4 \\
\hline
\end{tabular}


RASopathies Network and the Costello Syndrome Family Network, working together with clinicians and researchers. Patients, patient organizations, clinicians and researchers can work together in a more effective way to their mutual benefit. Not only with the goal of patient recruitment as is often done, but also to share and discuss basic science and clinical issues, setting forth a solid framework for future research, translational applications directed towards therapy and best practices for individuals.

More recently, patient representative organizations have become increasingly involved in the choice of the research topic and the formulation of a plan and methodology. Hopefully, the initiatives as formulated in the recent articles about the proceedings published by Gross et al. and Gripp et al. can lead to improved patient engagement in the whole research trajectory and with higher levels of participation according to the participation ladder of Arnstein, aiming at least for partnership (level 6) [24, 25].

\section{Limitations}

The framework by Rummel and Ballaine was not used earlier in healthcare [12]. However, because of the simple and clear definitions of this process model we have decided to use this framework. Arnstein's ladder is a well-known model displaying different levels of participation, ranging from manipulation to citizen control. Abma and Broerse stated that the ladder easily translates to the health field, although it only displays levels of participation without specifying how they may be achieved [37]. However, this was not the aim of our study.

The assessment of articles relied heavily on the content of the titles and abstract which were used for initial inclusion in this study. Often, the impact of engagement was not worked out, but only the engagement in the process was described. Moreover, the interpretation of the level of engagement was sometimes not as clear as described in this article, e.g. one can discuss if the patient recruitment via the patient organization is the same as collecting data in the research steps, and can be seen as a real engagement. Also, an higher level of engagement, according to the ladder of Arnstein, does not automatically mean that patients and / or their representatives are better engaged in the process.

\section{Future implications}

The current results do show a positive albeit still modest development of patient engagement over the last few years. However, it is important to continue and expand this development. Engagement in clinical research seem to be relatively high given the numbers, but is relatively low looking at the level of participation, with a score of level 3, informing. In contrast, the engagement level was the highest of all categories, when patients participated in developing clinical guidelines with a median engagement score at level 6, partnership.

Looking at the research steps, the lowest level of engagement was found when patients were engaged in collecting data (step 4) with a median score of level 3, informing. In contrary, when patients did engage in analyzing and interpreting data (research step 5), although the number of studies was low, the median engagement level was much higher, at level 5 , placation.

The studies found in this scoping review reveal an increase of patient engagement in earlier stages of the research process, for instance engaged in determining research topics. This way the research could be even more aligned to the needs and wishes of patients and thereby becoming more relevant. A well established way to engage patients and/or patient representative organizations is aiming to yield insights in the most important patients' needs. A patient research agenda will give researchers, policy makers and patient representative organizations better insight in what problems patients experience, help clarify potential blind spots in the professional field and shape future research programs [38, 39]. However, this is not automatically followed by patient engagement at higher levels of participation in programming, collecting data, data analysis, publication of the results and implementation, especially of original research studies. For this reason, in the Netherlands for example, a Dutch agenda is being developed, in a collaboration between the Dutch Noonan Syndrome Foundation and national scientific and clinical professionals. Such an agenda will support the enhancement of both focus and relevance of future studies on Noonan syndrome spectrum disorders, especially when patients stay involved in the research process.

\section{Acknowledgements \\ Several authors of this publication are members of the European Ref- erence Network for Developmental Anomalies and Intellectual Disability (ERN-ITHACA).}

\section{Authors' contributions}

DT: Designed the study, performed the scoping review, helped analyze the findings, writing up the results and contributed to writing the manuscript. JN: performed the scoping review, helped analyze the findings, writing up the results and contributed to writing the manuscript. EL: contributed to writing the manuscript. EW: writing up the results and contributed to writing the manuscript. CP: Writing up the results and contributed to writing the manuscript. JD: designed the study, performed the scoping review, helped analyze the findings, writing up the results and contributed to writing the manuscript. All authors read and approved the final manuscript.

Funding

None.

Availability of data and materials

All data generated or analysed during this study are included in this published article. 


\section{Declarations}

Ethical approval and consent to participate

Not applicable.

\section{Consent for publication}

Not applicable.

\section{Competing interests}

The authors declare that they have no competing interests.

\section{Author details}

${ }^{1}$ Department of Pediatrics, Amalia Children's Hospital, Radboud Institute for Health Sciences, Radboud University Medical Center, Nijmegen, The Netherlands. ${ }^{2}$ Department of Human Genetics, Radboud University Medical Center, Nijmegen, The Netherlands. ${ }^{3}$ Centre of Excellence for Neuropsychiatry, Vincent Van Gogh Institute for Psychiatry, Venray, The Netherlands. ${ }^{4}$ Donders Institute for Brain, Cognition and Behavior, Radboud University Nijmegen, Nijmegen, The Netherlands. ${ }^{5}$ Faculty of Science, Athena Institute, VU University, Amsterdam, The Netherlands. ${ }^{6}$ Dutch Noonan Syndrome Foundation, Nijkerk, The Netherlands.

Received: 30 May 2021 Accepted: 10 October 2021

Published online: 26 October 2021

\section{References}

1. Grant AR, Cushman BJ, Cave H, Dillon MW, Gelb BD, Gripp KW, et al. Assessing the gene-disease association of 19 genes with the RASopathies using the ClinGen gene curation framework. Hum Mutat. 2018;39(11):1485-93.

2. Villani A, Greer MC, Kalish JM, Nakagawara A, Nathanson KL, Pajtler KW, et al. Recommendations for cancer surveillance in individuals with RASopathies and other rare genetic conditions with increased cancer risk. Clin Cancer Res. 2017;23(12):e83-90.

3. Romano AA, Allanson JE, Dahlgren J, Gelb BD, Hall B, Pierpont ME, et al. Noonan syndrome: clinical features, diagnosis, and management guidelines. Pediatrics. 2010;126(4):746-59.

4. Rauen KA, Huson SM, Burkitt-Wright E, Evans DG, Farschtschi S, Ferner $\mathrm{RE}$, et al. Recent developments in neurofibromatoses and RASopathies: management, diagnosis and current and future therapeutic avenues. Am J Med Genet A. 2015;167A(1):1-10.

5. CACM P. Knowledge co-production in health research, policy and care practice. Patient involvement in health-related decisions. Amsterdam: VU University 2013.

6. Schölvinck AF, Broerse JE. A Research agenda from the patient perspective: a process of boundary work in a divided patient community. Science \& Public Policy. 2020.

7. Caron-Flinterman JF, Broerse JE, Bunders JF. The experiential knowledge of patients: A new resource for biomedical research? Soc Sci Med. 2005;60(11):2575-84.

8. Goodare $\mathrm{H}, \mathrm{Smith} \mathrm{R}$. The rights of patients in research. BMJ. 1995:310(6990):1277-8.

9. Edwards V, Wyatt K, Logan S, Britten N. Consulting parents about the design of a randomized controlled trial of osteopathy for children with cerebral palsy. Health Expect. 2011;14(4):429-38.

10. Entwistle VA, Sheldon TA, Sowden A, Watt IS. Evidence-informed patient choice. Practical issues of involving patients in decisions about health care technologies. Int J Technol Assess Health Care. 1998;14(2):212-25.

11. Forsythe LP, Szydlowski V, Murad MH, Ip S, Wang Z, Elraiyah TA, et al. A systematic review of approaches for engaging patients for research on rare diseases. J Gen Intern Med. 2014:29(Suppl 3):S788-800.

12. Rjb WC. Research methodology in business. New York: Harper \& Row Publications; 1963.

13. Arnstein SRA. ladder of citizen participation. J Am Inst Plann. 1969:35(4):216-24.

14. Levac D, Colquhoun H, O'Brien KK. Scoping studies: advancing the methodology. Implement Sci. 2010;5:69.
15. Arksey HOML. Scoping studies: towards a methodological framework. Int J Soc Res Methodol. 2005;8(1):19-32.

16. Tartaglia M, Mehler EL, Goldberg R, Zampino G, Brunner HG, Kremer H, et al. Mutations in PTPN11, encoding the protein tyrosine phosphatase SHP-2, cause Noonan syndrome. Nat Genet. 2001;29(4):465-8.

17. Cosgrove L, Shaughnessy AF, Shaneyfelt T. When is a guideline not a guideline? The devil is in the details. BMJ Evid Based Med. 2018;23(1):33-6.

18. Ouzzani M, Hammady H, Fedorowicz Z, Elmagarmid A. Rayyan-a web and mobile app for systematic reviews. Syst Rev. 2016;5(1):210.

19. Axelrad ME, Glidden R, Nicholson L, Gripp KW. Adaptive skills, cognitive, and behavioral characteristics of Costello syndrome. Am J Med Genet A. 2004;128A(4):396-400.

20. Croonen EA, Harmsen M, Van der Burgt I, Draaisma JM, Noordam K, Essink $M$, et al. Perceived motor problems in daily life: focus group interviews with people with Noonan syndrome and their relatives. Am J Med Genet A. 2016;170(9):2349-56

21. Garg S, Brooks A, Burns A, Burkitt-Wright E, Kerr B, Huson S, et al. Autism spectrum disorder and other neurobehavioural comorbidities in rare disorders of the Ras/MAPK pathway. Dev Med Child Neurol. 2017;59(5):544-9.

22. Grant AR, Hemphill SE, Vincent LM, Rehm HL. Reclassification of the BRAF p.lle208Val variant by case-level data sharing. Cold Spring Harb Mol Case Stud. 2018;4(5)

23. Gripp KW, Lin AE, Nicholson L, Allen W, Cramer A, Jones KL, et al. Further delineation of the phenotype resulting from BRAF or MEK1 germline mutations helps differentiate cardio-facio-cutaneous syndrome from Costello syndrome. Am J Med Genet A. 2007;143A(13):1472-80.

24. Gripp KW, Schill L, Schoyer L, Stronach B, Bennett AM, Blaser S, et al. The sixth international RASopathies symposium: precision medicine-From promise to practice. Am J Med Genet A. 2020;182(3):597-606.

25. Gross AM, Frone M, Gripp KW, Gelb BD, Schoyer L, Schill L, et al. Advancing RAS/RASopathy therapies: an $\mathrm{NCl}$-sponsored intramural and extramural collaboration for the study of RASopathies. Am J Med Genet A. 2020;182(4):866-76.

26. Johnson B, Goldberg-Strassler D, Gripp K, Thacker M, Leoni C, Stevenson D. Function and disability in children with Costello syndrome and Cardiofaciocutaneous syndrome. Am J Med Genet A. 2015;167A(1):40-4.

27. Korf B, Ahmadian R, Allanson J, Aoki Y, Bakker A, Wright EB, et al. The third international meeting on genetic disorders in the RAS/ MAPK pathway: towards a therapeutic approach. Am J Med Genet A. 2015:167A(8):1741-6.

28. Niemczyk J, Equit M, Borggrefe-Moussavian S, Curfs L, von Gontard A. Incontinence in persons with Noonan Syndrome. J Pediatr Urol. 2015;11(4):201 e1-5.

29. Pierpont ME, Magoulas PL, Adi S, Kavamura MI, Neri G, Noonan J, et al. Cardio-facio-cutaneous syndrome: clinical features, diagnosis, and management guidelines. Pediatrics. 2014;134(4):e1149-62.

30. Rauen KA, Hefner E, Carrillo K, Taylor J, Messier L, Aoki Y, et al. Molecular aspects, clinical aspects and possible treatment modalities for Costello syndrome: proceedings from the 1st International Costello Syndrome Research Symposium 2007. Am J Med Genet A. 2008;146A(9):1205-17.

31. Rauen KA, Schoyer L, McCormick F, Lin AE, Allanson JE, Stevenson DA, et al. Proceedings from the 2009 genetic syndromes of the Ras/ MAPK pathway: from bedside to bench and back. Am J Med Genet A. 2010;152A(1):4-24

32. Rauen KA, Schoyer L, Schill L, Stronach B, Albeck J, Andresen BS, et al. Proceedings of the fifth international RASopathies symposium: When development and cancer intersect. Am J Med Genet A. 2018;176(12):2924-9.

33. Stevenson DA, Schill L, Schoyer L, Andresen BS, Bakker A, Bayrak-Toydemir $P$, et al. The fourth international symposium on genetic disorders of the Ras/MAPK pathway. Am J Med Genet A. 2016;170(8):1959-66.

34. Templin L, Baumann C, Busa T, Heckenroth H, Pouvreau N, Toutain A, et al. Prenatal findings in cardio-facio-cutaneous syndrome. Am J Med Genet A. 2016;170A(2):441-5.

35. Heckert A, Forsythe LP, Carman KL, Frank L, Hemphill R, Elstad EA, et al. Researchers, patients, and other stakeholders' perspectives on challenges to and strategies for engagement. Res Involv Engagem. 2020;6:60.

36. Smith M, Alexander E, Marcinkute R, Dan D, Rawson M, Banka S, et al. Telemedicine strategy of the European Reference Network ITHACA for 
the diagnosis and management of patients with rare developmental disorders. Orphanet J Rare Dis. 2020;15(1):103.

37. Abma TA, Broerse JE. Patient participation as dialogue: setting resegrch agendas. Health Expect. 2010;13(2):160-73.

38. Abma TA, Pittens CA, Visse M, Elberse JE, Broerse JE. Patient involvement in research programming and implementation: A responsive evaluation of the Dialogue Model for research agenda setting. Health Expect. 2015;18(6):2449-64
39. Barnieh L, Jun M, laupacis A, Manns B, Hememlgan B. Determing research priorities through partnership with patients: an overview. Semin Dial 2015;28(2):141-6.

\section{Publisher's Note}

Springer Nature remains neutral with regard to jurisdictional claims in published maps and institutional affiliations.
Ready to submit your research? Choose BMC and benefit from:

- fast, convenient online submission

- thorough peer review by experienced researchers in your field

- rapid publication on acceptance

- support for research data, including large and complex data types

- gold Open Access which fosters wider collaboration and increased citations

- maximum visibility for your research: over $100 \mathrm{M}$ website views per year

At BMC, research is always in progress.

Learn more biomedcentral.com/submissions 